\title{
Abscessos em coluna vertebral de bezerros e cordeiros: aspectos neurológicos
}

\section{Abscesses in the vertebral column of calves and lambs: neurologic aspects}

\section{Abscesos en columna vertebral de terneros y corderos: aspectos neurológicos}

\section{Luiz Carlos Marques; ${ }^{1}$ Fabiano Antônio Cadioli; ${ }^{2}$ Augusto de Castro Netto; ${ }^{3}$ Larissa Gabriela Ávila; ${ }^{4}$ Júlio Carlos Canola; ${ }^{5}$ Antônio Carlos Alessi ${ }^{6}$}

Departamento de Clínica e Cirurgia Veterinária da Faculdade de Ciências Agrárias e Veterinárias da Universidade Estadual Paulista (FCAV/UNESP), Campus de Jaboticabal. Jaboticabal, SP, Brasil

\section{Resumo}

Objetivo: Descrever a ocorrência de abscessos na coluna vertebral de seis bezerros e dois cordeiros criados no Estado de São Paulo. Descrição: Os animais acometidos tinham entre 50 e 150 dias de idade. Os sinais clínicos eram caracterizados por ataxia e paralisia caudal à lesão compressiva da medula espinhal. Um bezerro apresentou abscesso no corpo da $6^{\mathrm{a}}$ vértebra cervical e $1^{\mathrm{a}}$ torácica, três bezerros apresentaram abscessos epidurais nos segmentos torácicos, um bezerro apresentou abscesso epidural no segmento lombar e outro apresentou abscesso epidural lombo-sacro. Dois cordeiros apresentaram abscessos epidurais lombares. Animais com abscessos nos segmentos torácicos ou lombares da coluna vertebral apresentaram paraplegia dos membros pélvicos, enquanto aquele com abscesso localizado em vértebra cervical apresentou tetraplegia. Arcanobacterium pyogenes, Escherichia coli e Salmonella spp. foram isolados dos bezerros. Conclusões: Nota-se que, apesar da grande evolução tecnológica na área de produção animal, simples medidas higiênico-sanitárias, particularmente aquelas relativas à desinfecção do umbigo dos recém-nascidos no pós-parto imediato, ainda deixam a desejar, acarretando doenças de difícil tratamento.

Palavras-chave: Coluna vertebral. Abscesso. Abscesso epidural. Infecções bacterianas do sistema nervoso central. Compressão da medula espinhal. Locomoção. Ataxia. Paralisia. Bovinos. Ovinos.

'Professor Adjunto de Clínica Médica de Ruminantes do Departamento de Clínica e Cirurgia Veterinária da FCAV/UNESP, Campus de Jaboticabal. CRMV-SP 2438 ${ }^{2}$ Doutorando do Curso de Pós-graduação em Medicina Veterinária, área de Clínica Médica Veterinária da FCAV/UNESP, Campus de Jaboticabal. CRMV-SP 10181

${ }^{3}$ Médico Veterinário Residente de Clínica Médica Veterinária da da FCAV/UNESP, Campus de Jaboticabal. CRMV-SP 15912

${ }^{4}$ Médica Veterinária Residente de Clínica Médica Veterinária da FCAV/UNESP, Campus de Jaboticabal. CRMV-SP 17513

${ }_{5}^{5}$ Professor Assistente Doutor de Radiologia Veterinária do Departamento de Clínica e Cirurgia Veterinária da FCAV/UNESP, Campus de Jaboticabal. CRMV-SP 1765 ${ }^{6}$ Professor Titular de Patologia Veterinária do Departamento de Patologia Veterinária da FCAV/UNESP, Campus de Jaboticabal. CRMV-SP 1871 
MARQUES, L. C. et al. Abscessos em coluna vertebral de bezerros e cordeiros. / Abscesses in the vertebral column of calves and lambs. Abscesos en columna vertebral de terneros y corderos. Rev. Educ. Contin. CRMV-SP/Contin. Educ. J. CRMV-SP, São Paulo, v. 7, n. $1 / 3$, p. $15-22,2004$

\section{Introdução}

Abscessos epidurais e do corpo das vértebras em ruminantes são comuns em animais jovens, especialmente em associação com infecções piogênicas do umbigo, abscessos pulmonares ou de outros sítios, tais como feridas contaminadas e enterites causadas por bactérias invasivas ( REBHUN, ${ }^{1} 1995$; RADOSTITIS et al., ${ }^{2}$ 2002). Septicemias ocorrem mais freqüentemente em neonatos, entretanto, os sinais clínicos relativos à compressão da medula espinhal por abscessos são evidenciados numa fase mais tardia, ou seja, em animais de dois a quatro meses de idade (SCOTT, ${ }^{3}$ 2004).

Os sítios de localização - mais comuns - dos abscessos da coluna vertebral em ruminantes são os segmentos compreendidos entre o coração e os rins (T5 a L3). O aumento de volume dos abscessos eventualmente afeta ou comprime a medula espinhal, causando ataxia e paralisia caudal à lesão. Animais com abscessos no segmento tóraco-lombar apresentam paralisia dos membros pélvicos, enquanto aqueles com abscessos nos segmentos da coluna cervical apresentam tetraplegia. Os sinais neurológicos surgem freqüentemente de modo repentino, a despeito da evolução crônica dos abscessos da coluna vertebral (ANDREWS et al., ${ }^{4}$ 2004).

A sintomatologia clínica sugere a localização aproximada do sítio da lesão e é importante para facilitar a investigação radiológica e a orientação quanto ao prognóstico e tratamento. O Quadro 1 mostra as síndromes clínicas gerais resultantes de lesões compressivas dos seis segmentos anatômicos funcionais da medula espinhal (SCOTT, 3,10 2002, 2004; BREWER, ${ }^{5}$ 1987).

Os agentes etiológicos envolvidos na grande maioria dos casos de bezerros são Arcanobacterium

Quadro 1 - Sinais clínicos das lesões compressivas da medula espinhal, caudal ao forame magno*

\section{Localização da lesão}

Cervical: C1 a C6

Cérvico-torácico: C6 a T2

Tóraco-lombar: T2 a L3

Lombo-sacro: $\mathrm{L} 4$ a S2

Sacro: S1 a S3

Sacrococcígea

(síndrome da cauda eqüina)

\section{Sinais clínicos}

Membros pélvicos são mais afetados do que os membros torácicos. Ataxia, dismetria, fraqueza muscular progressiva até completa paralisia que pode ser unilateral ou de todos os membros, porém, mais intensos nos membros pélvicos; reflexos espinhais normais a exacerbados; déficit proprioceptivo a despeito da manutenção da consciência; dor cervical que pode ser evidenciada pela rigidez do pescoço e dificuldades de movimentos da cabeça.

Ataxia, dismetria e fraqueza de todos os membros, porém, algumas vezes os membros torácicos são mais severamente afetados do que os membros pélvicos; déficit proprioceptivo consciente; reflexos dos membros torácicos diminuídos; reflexos dos membros pélvicos exacerbados; perda da sensibilidade superficial.

Membros torácicos normais; reflexos exacerbados nos membros pélvicos; ataxia, dismetria e fraqueza nos membros pélvicos; déficit proprioceptivo consciente em membros pélvicos; perda sensitiva superficial; posição de cão sentado com os membros pélvicos estendidos ao longo do abdome; o reflexo patelar e de retração do membro apresenta-se aumentado.

Membros torácicos normais; diminuição dos reflexos e/ou paresia da parte caudal dos membros pélvicos; perda sensitiva superficial e ausência de reflexos; posição de cão sentado.

Bexiga distendida e atonia do esfíncter anal.

Hipotonia; hipoalgesia; reflexos da cauda, região perineal e ânus diminuídos; atonia da bexiga e esfincter anal. 
pyogenes, Salmonella dublin e Salmonella typhimurium (SCOTT, ${ }^{3}$ 2004; BLOWEY; WEAVER, ${ }^{6}$ 2003). Pasteurella spp., Fusobacterium necrophorum, Streptococcus spp. e Brucella abortus cepa B19 também já foram isolados (REBHUM, ${ }^{1}$ 1995). Arcanobacterium pyogenes e Staphylococcus sp. são os agentes comumente isolados em ovinos jovens (FINLEY, ${ }^{7}$ 1975). Corynebacterium pseudotuberculosis também é uma causa comum em ovinos e caprinos adultos (LINKLATER; SMITH, ${ }^{8}$ 1993; SMITH, ${ }^{9}$ 2002).

O objetivo do presente trabalho é descrever os aspectos clínicos e anatomopatológicos de seis bezerros e dois cordeiros com abscessos vertebrais, atendidos no Hospital Veterinário "Governador Laudo Natel" da Faculdade de Ciências Agrárias e Veterinárias da Universidade Estadual Paulista (FCAV/ UNESP), Campus de Jaboticabal, Jaboticabal, SP, nos anos de 2001 a 2004.

\section{Descrição dos Casos}

Descreve-se a ocorrência de abscessos envolvendo a coluna vertebral em seis bezerros, sendo três fềmeas e três machos, e em dois cordeiros.

A bezerra B1 era mestiça com dois meses e meio de idade, a B2 era da raça Simental com 50 dias de idade e a B3 da raça Holandesa malhada de preto com aproximadamente cinco meses. Dos machos, um era da raça Limousin (B4) com cinco meses de idade, o B5 era mestiço com três meses de idade e o B6 da raça Nelore com cerca de dois meses de idade.

Os dois cordeiros (O1 e O2) eram machos e sem raça definida, sendo o cordeiro O1 de aproximadamente cinco meses de idade e o cordeiro $\mathrm{O} 2$ com três meses de idade.

Os bezerros foram submetidos a exames clínicos, colheita de sangue para hemograma e colheita e análise do líquido cefalorraquidiano (LCR). ${ }^{11-13}$ Foram realizados ainda exames radiológicos da coluna vertebral de todos os bezerros. A bezerra B3 foi subme- tida à mielografia contrastada de acordo com a técnica preconizada por Uri Bargai et al., ${ }^{14}$ em 1989.

Por motivos de custo-benefício, os cordeiros foram apenas submetidos a exames clínicos e necroscópicos.

Todos os animais foram submetidos à eutanásia, utilizando-se para tal $1 \mathrm{~g}$ de tiobarbitúrico e $500 \mathrm{mg}$ de succinil colina, aplicados por via intravenosa. As necropsias foram realizadas imediatamente após as eutanásias, e especial atenção foi dada ao exame da coluna vertebral e à identificação de focos infecciosos em outros tecidos ou órgãos. No momento das necropsias, ainda colheram-se secreções purulentas dos abscessos para cultura e identificação microbiológica.

\section{Discussão}

Todos os animais foram encaminhados para exames no momento em que apresentaram, repentinamente, disfunções motoras e sensoriais envolvendo os membros torácicos e/ou pélvicos.

As bezerras (B1 e B2) apresentaram diarréia na segunda semana de vida. Os exames clínicos revelaram reflexos motores e sensoriais dos membros torácicos normais, reflexos dos membros pélvicos e da cauda exacerbados (rigidez), ataxia, dismetria, fraqueza e falta de coordenação motora (Figura 1), perda sensitiva superficial e déficit proprioceptivo nos membros pélvicos. Ao tentar levantar os animais assumiam posição de cão sentado, com os membros pélvicos estendidos ao longo do abdome.

A B3 não tinha histórico prévio de doença, entretanto, apresentou repentinamente dificuldades de locomoção e fraqueza em todos os membros. Após um dia do início dos sintomas, o animal deitou-se e não conseguiu mais se levantar. $\mathrm{O}$ exame clínico revelou tetraplegia, reflexos espinhais de normais a exacerbados; déficit proprioceptivo a despeito da manutenção da consciência, dor cervical evidenciada pela rigidez do pescoço e orelhas, e dificuldades de movimentos da cabeça, a despeito da manuten- 
ção do apetite. Os reflexos patelares e de retração do membro tinham aumentado. Os leucogramas de todas as bezerras revelaram apenas neutrofilia com linfocitopenia relativa. Os exames do LCR demonstraram aumento na contagem de células $(100,60 \mathrm{e}$ 80 células $/ \mathrm{mm}^{3}$ ) para o B1, B2 e B3, respectivamente. As células predominantes $(80 \%)$ eram polimorfonucleares. Tratamentos realizados em todas as bezerras com oxitetraciclina, sulfonamida associada ao trimetoprim e flunixina meglumina, por um período aproximado de 15 dias, não resultaram em nenhuma melhora clínica significativa. Os animais foram submetidos à eutanásia e necropsia, e apesar de os exames radiológicos não terem revelado alterações significativas nas estruturas anatômicas da coluna vertebral das B1 e B2, visualizou-se a presença de abscessos extradurais nos segmentos T11 e T12 (Figura 2), dos quais foram isolados Escherichia coli e A. pyogenes, respectivamente.

A mielografia realizada na $\mathrm{B} 3$ demonstrou desvio ventro-dorsal da medula espinhal entre a $6^{\mathrm{a}}$ vértebra cervical e a $1^{\mathrm{a}}$ vértebra torácica (Figura 3 ). No sítio do desvio medular, à necropsia, detectou-se abscesso no corpo da vértebra C6, com envolvimento também do espaço epidural ventral (Figura 4). Detectou-se ainda um abscesso com aproximadamente $5 \mathrm{~cm}$ de diâmetro junto à pleura parietal nas proximidades craniais do xifóide. Neste caso, não foi possível isolar o agente bacteriano. Os sinais clínicos, observados nas bezerras B1 e B2, foram compatíveis com aqueles descritos em casos com processos compressivos da medula espinhal envolvendo o segmento anatômico funcional tóraco-lombar. Da mesma forma, os sintomas observados na B3 são compatíveis com aqueles descritos em casos de compressões da medula espinhal envolvendo o segmento cérvico-torácico, conforme divisão anatômica funcional estabelecida por Brewer $^{5}$ (1987) e $\operatorname{Scott}^{3}$ (2004).

E. coli é patógeno comumente isolado de fezes de bezerros neonatos com diarréia, e dentre as diversas cepas, estão aquelas invasivas que podem desencadear septicemia, com possibilidades de provocar danos em outros tecidos ou órgãos. ${ }^{2,4}$ Assim, é possível que exista alguma correlação entre a diar- réia apresentada pelo $\mathrm{B} 1$ e o desenvolvimento do abscesso extradural. No B2 em particular, a correlação dos abscessos com doenças prévias não foi estabelecida, considerando que $A$. pyogenes não é um agente etiológico que figura dentre os que causam enterites na espécie bovina.

Dentre os machos, o B4 tinha histórico de inflamação e míase umbilical no período pós-natal imediato. A palpação do umbigo revelou a presença de um cordão fibroso de consistência firme sem pontos de flutuação sugestivos de abscessos ou processos inflamatórios ativos. Havia diminuição dos reflexos e/ou paresia da parte caudal dos membros pélvicos, perda sensitiva superficial e ausência de reflexos da cauda e atonia do esfincter anal, com discreto prolapso da mucosa. $\mathrm{O}$ animal estava em decúbito esternoabdominal e não conseguia se levantar.

O B5 e o B6 apresentavam onfaloflebites. Os exames clínicos revelaram nos membros pélvicos: reflexos exacerbados, ataxia, fraqueza e déficit proprioceptivo, além de posição de cão sentado com os membros estendidos ao longo do abdome e perda sensitiva superficial (Figura 5). Ainda notou-se no B5 escoriações e discreto relaxamento do ânus com prolapso da mucosa.

Os leucogramas revelaram no B5 e no B6 leucocitose com neutrofilia e linfocitopenia relativa. Os exames do LCR demonstraram aumento na contagem de células, 120 e 80 células $/ \mathrm{mm}^{3}$, respectivamente. As células predominantes $(80 \%)$ eram também constituídas por polimorfonucleares. O B4 não apresentou aumento na contagem de células do LCR, sendo a neutrofilia a única alteração constatada. Radiografias da coluna vertebral não revelaram alterações das estruturas ósseas e dos espaços intervertebrais. Tratamentos realizados em todos os bezerros, à semelhança do que foi realizado nas bezerras, também não resultaram em nenhuma melhora clínica significativa.

Os bezerros foram submetidos à eutanásia $\mathrm{e}$ necropsiados, detectando-se abscessos nos espaços intervertebrais T12-T13 no B5 e L3-L4 no B6, dos quais foram isolados Salmonella sp. No B4 visua- 
lizou-se abscesso no espaço intervertebral lombosacro, além da repleção vesical. Neste caso não foi possível isolar e identificar o agente causal. Os sinais clínicos, observados nos bezerros B5 e B6, foram compatíveis com aqueles descritos em casos de processos compressivos da medula espinhal envolvendo o segmento tóraco-lombar; e os sinais clínicos observados na B4 são compatíveis com aqueles descritos em casos de compressões da medula espinhal envolvendo o segmento lombo-sacro, conforme divisão anatômica funcional estabelecida por Brewer $^{5}$ (1987) e $\operatorname{Scott}^{3}$ (2004).

Abscessos da coluna vertebral foram evidenciados por Rebhun ${ }^{1}$ (1995) e $\operatorname{Scott}^{3}$ (2004) em bezerros de dois a quatro meses de idade. Entretanto, na presente observação as idades dos bezerros variaram de 50 a 150 dias, portanto, em faixa etária mais ampla do que a verificada na literatura compilada.

Os cordeiros eram provenientes da mesma propriedade, em que as condições de manejo sanitário eram precárias. Ambos apresentavam onfaloflebite. Os exames clínicos revelaram, nos membros pélvicos, diminuição dos reflexos e/ou paresia da parte caudal, e perda sensitiva superficial, a despeito da manutenção do apetite e consciência. A necropsia revelou a presença de abscesso intervertebral entre os segmentos L3-L4 no O1e abscesso extradural envolvendo os segmentos L4-L5 no O2 (Figura 6). Nestes casos, não foram realizados exames complementares, entretanto, $\operatorname{Scott}^{10}$ (2002) relata que Arcanobacterium pyogenes e Staphylococcus spp. são os agentes freqüentemente associados a lesões infecciosas da coluna vertebral em cordeiros. Segundo Pughi ${ }^{15}$ (2002), abscessos vertebrais em ovinos podem ser conseqüência de linfadenite caseosa, onfaloflebite ou septicemia. Nos casos estudados, não foram evidenciadas lesões sugestivas de linfadenite caseosa, devendo, portanto, a causa estar associada com outras bactérias piogênicas, possivelmente decorrente de septicemias oriundas das infecções umbilicais.
Particularmente, nos bezerros e nos cordeiros, parece existir correlação direta entre as infecções umbilicais e o desenvolvimento de abscessos da coluna vertebral. A gravidade da sintomatologia observada nos animais portadores de abscessos epidurais parece estar diretamente correlacionada ao grau de compressão da medula espinhal, pois, segundo Jubb et al. ${ }^{16}$ (1993), a dura-máter é raramente penetrada pelos agentes infecciosos.

Quanto ao diagnóstico diferencial, devem-se considerar outros processos compressivos medulares que desencadeiam sintomas semelhantes, tais como as lesões traumáticas e neoplasias. Leucose enzoótica com linfonodos comprimindo a medula espinhal é uma condição rara em bezerros, ocorrendo com freqüência apenas em bovinos adultos. ${ }^{2}$

\section{Conclusões}

Os métodos auxiliares de diagnóstico (análise do LCR e radiografias), na maioria dos casos não permitem conclusão diagnóstica de abscessos da coluna vertebral, uma vez que na grande maioria dos casos não se verificam alterações significativas (SHERMAN; AMES, ${ }^{17}$ 1986). Dessa forma, ressalta-se a importância da utilização de técnicas diagnósticas especiais, tais como as mielografias contrastadas, que apesar de dispendiosas, permitem estabelecer com maior segurança a localização exata da lesão, possibilitando, assim, o estabelecimento de um prognóstico mais adequado para cada caso, norteando possíveis medidas terapêuticas.

Nota-se que apesar da grande evolução tecnológica na área de produção animal, simples medidas higiênico-sanitárias, particularmente aquelas relativas à desinfecção do umbigo dos recémnascidos no pós-parto imediato, ainda deixam a desejar, acarretando doenças de difícil tratamento e gerando prejuízos irreparáveis à pecuária brasileira. 
MARQUES, L. C. et al. Abscessos em coluna vertebral de bezerros e cordeiros. / Abscesses in the vertebral column of calves and lambs. / Abscesos en columna vertebral de terneros y corderos. Rev. Educ. Contin. CRMV-SP/Contin. Educ. J. CRMV-SP, São Paulo, v. 7, n. $1 / 3$, p. $15-22,2004$

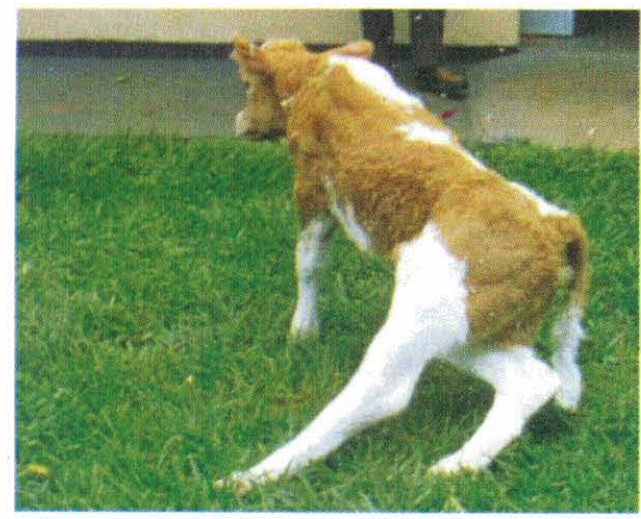

Figura 1 - Bezerra (2) com abscesso epidural no segmento T11-T12. Notar ataxia, déficit proprioceptivo e falta de coordenação motora dos membros pélvicos. Hospital Veterinário "Governador Laudo Natel" da FCAV/ UNESP, Campus de Jaboticabal, Jaboticabal, SP, em 2003

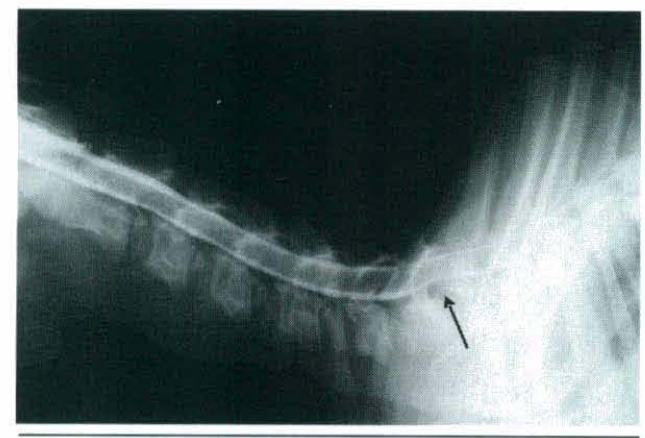

Figura 3 - Mielografia de coluna vertebral de bezerra (3). Notar desvio ventro-dorsal do trajeto medular (seta) no segmento C6-T1. Hospital Veterinário "Governador Laudo Natel" da FCAV/UNESP, Campus de Jaboticabal, Jaboticabal, SP, em 2002

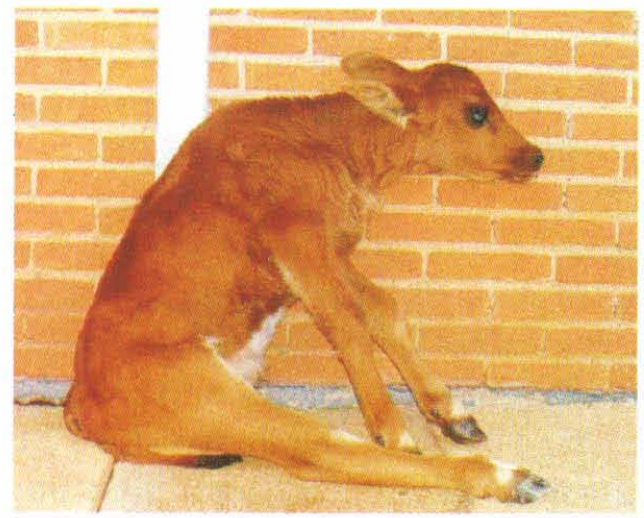

$\overline{\text { Figura } 5 \text { - Bezerro com abscesso em corpo }}$ vertebral, no segmento T11-T12. Notar posição de cão sentado e membros pélvicos estendidos. Hospital Veterinário "Governador Laudo Natel" da FCAV/UNESP, Campus de Jaboticabal, Jaboticabal, SP, em 2004

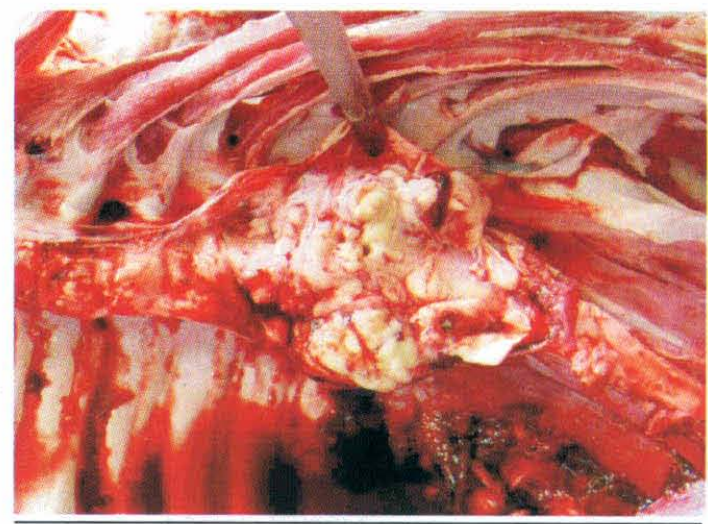

Figura 2 - Aspecto macroscópico de abscesso da coluna vertebral envolvendo o espaço epidural no segmento T11-T12 (bezerra 1). Hospital Veterinário "Governador Laudo Natel" da FCAV/UNESP, Campus de Jaboticabal, Jaboticabal, SP, em 2001

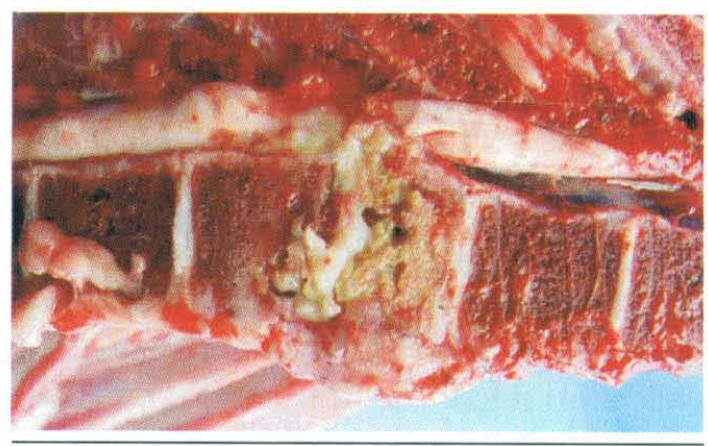

Figura 4 - Aspecto macroscópico de coluna vertebral de bezerra (3). Notar coleção purulenta no corpo vertebral (T1) e no canal medular. Hospital Veterinário "Governador Laudo Natel" da FCAV/UNESP, Campus de Jaboticabal, Jaboticabal, SP, em 2002.
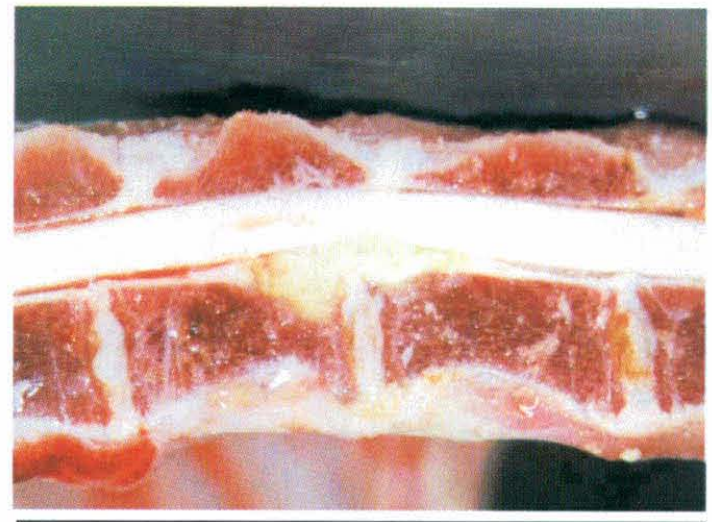

Figura 6 - Aspecto macroscópico de coluna vertebral de cordeiro (O2). Notar coleção purulenta extradural e desvio do eixo medular (L3L4). Hospital Veterinário "Governador Laudo Natel" da FCAV/UNESP, Campus de Jaboticabal, Jaboticabal, SP, em 2003 


\section{Abstract}

Objective: To document the occurrence of vertebral column abscesses in six calves and two lambs raised in the State of São Paulo, Brazil. Description: The affected calves were aged between 50 and 150 days. Clinical signs consisted of ataxia and paralysis caudal to the compressive lesion in the vertebral column. In one calf, the abscess affected the body of the $6^{\text {th }}$ cervical and $1^{\text {st }}$ thoracic vertebrae, three calves had epidural abscesses in the thoracic segments, one calf had epidural abscess in the lumbar segment and another calf had epidural lumbosacral abscess. Both lambs had lumbar epidural abscesses. Animals suffering from abscesses in the thoracic or lumbar segments of the vertebral column presented with paraplegia of pelvic limbs, while tetraplegia was observed when the abscess affected the cervical vertebra. Arcanobacterium pyogenes, Escherichia coli and Salmonella spp. were isolated from the affected calves. Conclusions: Despite the great technological evolution in animal production, it is clear that the lack of simple hygienic procedures, such as umbilical disinfection of newborns, are still not correctly performed and cause severe diseases.

Keywords: Spine. Abscess. Epidural abscess. Central nervous system bacterial infections. Spinal cord compression. Locomotion. Ataxia. Paralysis. Cattle. Sheep.

\section{Resumen}

Objetivo: Describir la presencia de abscesos en la columna vertebral de seis terneros y dos corderos criados en el Estado de São Paulo, Brasil.Descripción: los animales afectados tenían entre 50 y 150 días de edad. Los animales presentaron sintomatología caracterizada por ataxia y parálisis caudal a la lesión que estaba comprimiendo la médula espinal. Un ternero presentó absceso en el cuerpo de la $6^{\mathrm{a}}$ vértebra cervical y de la $1^{\mathrm{a}}$ torácica; tres terneros presentaron abscesos epidurales en los segmentos torácicos; un ternero presentó absceso epidural en el segmento lumbar y el otro ternero presentó absceso epidural lumbosacro. Los dos corderos presentaron abscesos epidurales lumbares. Los animales con abscesos en los segmentos torácicos y lumbares de la columna vertebral, presentaron paraplejia de los miembros pelvianos, en cuanto el animal con el absceso localizado en la vértebra cervical presentó tetraplejia. Se aislaron de los terneros las bacterias Arcanobacterium pyogenes, Escherichia coli y Salmonella spp.Conclusiones: se observa que a pesar del gran avance tecnológico en el área de producción animal, algunas medidas higiénico sanitarias simples, principalmente las relativas a la desinfección del obligo de los recién nacidos inmediatamente después del parto, dejan mucho que desear, ocasionando enfermedades de difícil tratamiento.

Palabras-clave: Columna vertebral. Absceso. Absceso epidural. Infecciones bacterianas del sistema nervioso central. Compresión de la médula espinal. Locomoción. Ataxia. Parálisis. Bovinos. Ovinos.

\section{Referências}

1. REBHUN, W. C. Diseases of dairy cattle. Baltimore: Williams \& Wilkins, 1995. 530 p.

2. RADOSTITS, O. M. et al. Clínica veterinária. 9. ed. Rio de Janeiro: Guanabara Koogan, 2002. $1737 \mathrm{p}$.
3. SCOTT, P.R. Neurological disorders. In: ANDREWS, A. H. et al. Bovine medicine. 2. ed. Oxford: Blackwell, 2004. p. 890-916.

4. ANDREWS, A. H. et al. Bovine medicine. 2. ed. Oxford: Blackwell, 2004. 1218 p. 
5. BREWER, B. D. Examination of bovine nervous system. Veterinary Clinics of North America, v. 3, p. 13-24, 1987.

6. BLOWEY, R. W.; WEAVER, A. D. Color atlas of diseases and disorders of cattle. 2. ed. London: Elsevier, 2003. 223 p.

7. FINLEY, G. G. A survey of vertebral abscesses in domestic animals in Ontario. Canadian Veterinary Journal, v. 16, p. 114-117, 1975.

8. LINKLATER, K. A.; SMITH, M. C. Diseases and disorders of the sheep and goat. Saint Louis: Mosby, 1993. $256 \mathrm{p}$.

9. SMITH, M. O. Diseases of nervous system. In: SMITH, B. P. Large animal internal medicine. 3. ed. Saint Louis: Mosby, 2002. p. 982-984.

10. SCOTT, P.R. Others nervous diseases. In: MARTIN, W. B; AITKEN, I. D. Diseases of sheep. 3. ed. Edinburgh: Blackwell, 2002. p. 228-239.

11. Ferreira neto, J. M. et al. Patologia clínica veterinária. Belo Horizonte: Rabeco, 1981. 293 p.
12. ROSENBERGER, G. Exame clínico dos bovinos. 2. ed. Rio de Janeiro: Guanabara Koogan, 1983. $429 \mathrm{p}$.

13. SCHALM, O. W. et al. Veterinary hematology. 3. ed. Philadelphia: Lea \& Febiger, 1975. 807 p.

14. URI BARGAI, I. A. B. et al. Bovine radiology. Ames: State University Press, 1989. 198 p.

15. PUGH, D. G. Sheep and goat medicine. Philadelphia: Saunders, 2002. 468 p.

16. JUBB, K. V. F.; HUXTABLE, C. R. Nervous system. In: JUBB, K. V. F. et al. Pathology of domestic animals. 4. ed. San Diego: Academic Press, 1993. v. 1, p. 385.

17. SHERMAN, D.M.; AMES, T. R. Vertebral body abscess in cattle: a review of five cases. Journal of the American Veterinary Medical Association, v. 168, p.608-611, 1986. 